\title{
Even more evidence for the emptiness of plurality: An experimental investigation of plural interpretation as a species of implicature*
}

\author{
Hazel Pearson \\ Harvard University
}

\author{
Manizeh Khan \\ Harvard University
}

\author{
Jesse Snedeker \\ Harvard University
}

\begin{abstract}
In two experiments, we test a family of theories that treat the "more than one' meaning component of the plural morpheme as an implicature rather than an inherent part of its semantics (Sauerland, Anderssen \& Yatsushiro 2005, Spector 2007, Zweig 2009). We find that under certain circumstances, this meaning component appears to be canceled, in the manner of an implicature. Our findings suggest that the implicature is relatively difficult to cancel, and that cancelation is facilitated by employing a linguistic environment in which plural marking contributes to the presupposed but not the asserted content. The notion that implicatures may be more easily canceled when they contribute to the presuppositional component is a novel contribution of the study.
\end{abstract}

Keywords: plurality, implicature, number agreement, experimental semantics

\section{Introduction}

There is a well-known puzzle in the theoretical semantics literature concerning the distinction between singular and plural in natural language. ${ }^{1}$ Pre-theoretically, the plural morpheme seems to mean 'more than one', yet sometimes we use plural morphology without necessarily having in mind a set of more than one object. Consider the following:

\section{(1) There are no books on Mary's desk.}

* We thank Susan Carey, Greg Carlson, Gennaro Chierchia, Chris Cummins, Hrayr Khanjian, Daniele Panizza, Jacopo Romoli, Eytan Zweig, and the audiences of Linguistic Evidence 2010, SALT 20 and the Harvard Scalar Implicature Summer Workshop. Special thanks to our Research Assistant Tabitha Carlson.

1 For relevant discussion, see Schwarzschild 1996, Chierchia 1998, Sauerland 2003, Sauerland et al. 2005 and Spector 2007. 
(2) If there are books on Mary's desk, she should lock her door when she leaves.

(3) Are there books on your desk?

If there is exactly one book on Mary's desk, (1) is false. In the same context, Mary should lock her door according to (2), and the answer to (3) is 'yes'. Yet (4) is false in this context.

(4) There are books on Mary's desk.

In response to the apparent paradox arising from data like (1-4), a number of researchers have rejected the notion that the semantics of the plural morpheme incorporates a 'more than one' condition (henceforth: a multiplicity condition). ${ }^{2}$ They propose instead that this meaning component arises as an implicature (Sauerland 2003, Sauerland et al. 2005, Spector 2007, Zweig 2009). In this paper, we report the findings of an experimental investigation of implicature-based theories of plural marking, focusing on the theory proposed in Sauerland's work.

In a recent series of papers, Sauerland suggests that it is part of the meaning of the singular morpheme that it can only combine with DPs that denote atoms. ${ }^{3}$ Call this the atomicity presupposition of the singular; the proposed semantics for singular morphology is stated in (5a). According to this proposal, there is no corresponding presupposition associated with plural morphology; that is, the plural morpheme carries no inherent constraint such that the DP it combines with must denote an individual of cardinality greater than one (5b).

$$
\text { a. } \llbracket \mathrm{SG} \rrbracket=\lambda \mathrm{x} \in \mathrm{D}_{e}: \operatorname{ATOM}(\mathrm{x}) \cdot \mathrm{x}
$$

b. $\llbracket \mathrm{PL} \rrbracket=\lambda \mathrm{x} \in \mathrm{D}_{e} \cdot \mathrm{x}$

A puzzle remains, of course: if the plural morpheme simply denotes the identity function on individuals, why can I not utter (4) when there is only one book on Mary's desk? That is, why does the plural often mean (or seem to mean) 'more than one'? Sauerland's solution is that the multiplicity condition is derived via an implicature.

To see this, suppose that the semantics in (5) is correct. That is, the singular carries an atomicity presupposition, while the plural has no inherent presupposition. Suppose further that 'Maximize Presupposition' holds: given two expressions $\mathrm{E}_{1}$ and $\mathrm{E}_{2}$, whichever carries more presuppositional content is selected, all else being equal (Heim 1991). Since SG carries a presupposition that has no counterpart in PL,

2 The term 'multiplicity condition' is borrowed from Zweig (2009).

3 While Sauerland assumes that number features are realized on a head that takes a DP as its complement, Chierchia (2007) provides arguments that they occupy a lower position. We do not take a position on this issue, but assume Sauerland's implementation for expository purposes. 
speakers will use it whenever the constraints on its usage are met: that is, whenever the DP with which it combines denotes an atom. Use of the plural is therefore associated with an implicature that the atomicity presupposition is not satisfied that is, that the DP denotes an entity consisting of more than one object.

For our purposes, these are the crucial components of Sauerland's theory. One of the theory's virtues is that it provides an explanation for the distribution of readings exemplified above. On this account, the multiplicity condition is a close relative of scalar implicature (SI). Like scalar implicatures, it arises as a result of competition with alternatives that are determined by replacing one item with another item from the same scale $-<\mathrm{PL}, \mathrm{SG}>$ in the present case. One might then expect that the factors determining whether the multiplicity condition is present (as in (4)) or not (as in (1-3)) will be the same ones that determine whether SIs are present. If so, the multiplicity condition will have the same distribution as scalar implicatures. Indeed, it turns out that the environments in which SIs are generally suspended - so-called downward entailing (DE) contexts - are those in which the multiplicity condition is absent; the restrictor of 'no' (1), the antecedent of a conditional (2) and yes-no questions (3) exemplify these environments.

On the other hand, scalar implicature is not the only linguistic phenomenon that exhibits sensitivity to polarity. The distribution of Negative Polarity Items (NPIs) such as 'any' has been convincingly shown to be influenced by entailment properties. In particular, they are licensed only in DE contexts (Fauconnier 1975, Fauconnier 1979, Ladusaw 1979, Ladusaw 1980,b). A competing hypothesis is therefore that the distribution of the multiplicity condition is related to the distribution of NPIs rather than SIs. Consider the details. Suppose that the multiplicity condition is built into the semantics of plural marking after all. Suppose further that in DE environments with bare plural nominals, there is an unpronounced 'any' that takes the plural noun phrase as its complement. Conceivably, it is the semantics of this determiner that is responsible for the apparent absence of the multiplicity condition. It is beyond the scope of this paper to spell out a semantics for 'any' that would produce this result. The idea is similar to that proposed by Chierchia (1998), who attributes the absence of the multiplicity condition with plurals in the complement of 'no' to the semantics of 'no'. By so doing, he is able to maintain the assumption that the semantics of plural marking incorporates a multiplicity condition, but explain why this condition is absent when a plural nominal occurs in the complement of 'no'. We think that in principle it is possible to extend this idea to bare plurals in DE environments by blaming the absence of the multiplicity condition on the semantics of 'any'. If so, one could explain the distribution of the multiplicity condition without appeal to implicature. The disappearance of the multiplicity condition in DE environments is therefore not conclusive evidence that it is an implicature. In our study, we focused on another property that has been claimed to be a hallmark of scalar implicatures: 
cancelability (Grice 1975). We conducted an experimental study to discern whether the multiplicity condition can be canceled in upward entailing contexts. If so, this would constitute additional evidence in favor of an implicature-based theory of plural marking.

The remainder of this paper proceeds as follows. In section 2, we describe previous experimental work investigating implicature-based theories of plural marking, and highlight some of its limitations. In section 3, we report on two experiments that test whether plural DPs can ever be interpreted as referring to singleton sets in non-DE contexts. Such a result would suggest that the multiplicity condition may be subject to cancelation in Grice's sense. In Experiment 1, we found that participants were unwilling to interpret plurals as denoting atomic individuals, and hence that no multiplicity implicature was canceled. In Experiment 2, we found that adding a presupposition trigger to our stimuli increased tolerance of singleton sets as exemplars of plural DPs. Section 4 discusses our findings, which lend support to implicature-based theories of the plural. The multiplicity implicature is relatively difficult to cancel, but cancelation is facilitated by including plural morphology within presupposed rather than asserted material. More generally, our findings suggest that implicatures are more readily canceled when they are part of the presupposed content of a sentence, rather than part of the asserted content. This is a novel result with few precedents in the literature. Section 5 concludes the paper and points to directions for future research.

\section{Previous experimental work}

We know of only one published study exploring an implicature-based theory of plural semantics (Sauerland et al. 2005). The authors reason that the multiplicity condition should have a similar acquisition profile to scalar implicatures: that is, it should develop relatively late in child language. ${ }^{4}$ They investigated this prediction by employing a truth value judgment task with 14 English-speaking children aged $3 ; 4$ to $5 ; 9$. On the critical trials, a puppet asked questions of the form 'Does a girl have noses?' or 'Does a dog have tails?'. The authors reasoned that if implicature were responsible for the multiplicity condition, it would be absent from the interpretations assigned to the questions by children, and hence they would answer 'yes'. Comparison was with a follow-up study which showed that adults

4 We adopt Sauerland and colleagues' assumptions in order to explain the logic of the study. However, recent work casts doubt on their initial premise that young children simply do not compute scalar implicatures (for review, see Pouscoulous \& Noveck in press, Noveck \& Reboul 2008). Rather, their interpretation depends on the particular scalar implicature at hand and the demands of the task (Barner \& Bachrach 2010), and they gradually become more likely to apply the implicature as they get older. 
overwhelmingly answer 'no' to these questions. By contrast, $96 \%$ of the child subjects answered in the affirmative. The authors take these results as suggesting that the multiplicity condition is acquired relatively late and that, in this respect, it mirrors the behavior of scalar implicatures.

There are several limitations to this study. First, Sauerland and colleagues point out that their results may have been affected by the use of yes-no questions environments which are arguably downward entailing, and in which the multiplicity condition appears to disappear, as we have seen above. In response, they point out that there is controversy over whether these environments are in fact downward entailing, and argue that the data from adult performance show that a "more than one' reading is indeed assigned to the plural morpheme in the environments tested in the experiment. The authors attribute the difference between their stimuli and yes-no questions such as (3) to a distinction between 'information seeking questions' and 'exam type questions'. The speaker who asks a question of the first type is presupposed not to know the answer, while the speaker who asks the second type of question is presupposed to be already aware of the relevant facts. It is hypothesized that information seeking questions suspend the implicature, while exam type questions license it. However, it is unclear that this distinction is relevant to their experiment, as it is explicitly denied that the puppet asking the questions is well-informed about the answers. The context given in the experiment has it that the alien is genuinely trying to find out things about life on earth - matters which he is unaware of. Hence it seems plausible that children are interpreting these as information seeking questions, rendering the move to impute to children a failure to calculate a multiplicity implicature unwarranted. ${ }^{5}$

Second, the difference between the children and adults could reflect limitations in children's knowledge of generics rather than non-adult understanding of plurals. In these stimuli, the singular subject DP receives a kind-oriented interpretation. Generic sentences with bare plural subjects license dependent plurals: an adult would answer in the affirmative to questions like 'Do girls have noses?', or 'Do boys have tongues?'. It is possible that the children had a non-adult understanding of the licensing conditions on dependent plurals, and interpreted the singular subject of the stimuli as a licensor. The results of the study would then reflect interpretation of the direct object as a dependent plural, rather than failure to calculate a multiplicity implicature.

5 These remarks do not address the question of why adults answered 'no' to the critical questions; that is, why the implicatures are not suspended, unlike with the yes-no question in (3). Spector (2007) observes that in downward entailing environments, while the plain multiplicity condition is absent, a flavor of it survives in the form of a modal implicature. For example, 'Does a girl have noses' implicates that a girl might in principle have more than one nose. It seems that it is this that adult subjects were denying in their answers. 


\section{Our study}

\subsection{Experimental set-up}

Huang, Snedeker \& Spelke (under review) employ a covered box task with 2- and 3 - year olds and adults in order to investigate whether upper-bounded readings of numerals arise via scalar implicature, or are determined by the semantics of the numeral. There is a striking parallel between this issue and that of the meaning of plural morphology: in both cases, we are interested in knowing whether a particular aspect of an item's meaning is part of its semantics, or rather is pragmatically derived. The experimental set-up involves three boxes; the contents of two of the boxes are visible to experimenter and subject, while the third box is covered. In the critical trials in the Huang et al. paper, instructions are of the form 'Give me the box with two cookies'. On display are a box with one cookie, a box with three cookies and a covered box. If the numeral is typically accompanied by an SI, it is expected to be canceled given the context because no visible box containing exactly two cookies is available, and so the subject will select the box with three cookies, thereby satisfying the experimenter's request. If, on the other hand, numerals have an exact semantics, the subject will reject both boxes, conclude that the covered box must be the one that satisfies the description, and pick it up. Huang and colleagues found that participants chose the covered box in the critical trials, suggesting that numerals have an exact semantics. They verified that the covered box task is suitable for testing for the presence of scalar implicatures by running a follow-up experiment involving the scalar term 'some'.

We adopted an analogous procedure to test the cancelability of the multiplicity condition. Before describing the method in detail, we should discuss a reservation that one might have about employing the covered box task for this purpose. The paradigm exploits cancelability as a hallmark of implicatures. However, if the multiplicity condition is an implicature, it seems that doubt is cast on the assumption that all implicatures are cancelable. The continuation in (6) creates a typical cancelation environment, yet the resulting discourse is infelicitous.

(6) ?? John has books. In fact, he has one.

Chierchia, Fox \& Spector (to appear) use data like this to argue that the multiplicity implicature is obligatory. If so, it would be no argument against Sauerland's theory if the covered box task revealed that participants were unwilling to cancel it. In reply, we will merely point out that whether this implicature is cancelable or obligatory is far from being a settled question. For instance, Zweig (2009) develops an implicature-based account of dependent plurals, and provides examples of these implicatures being canceled. We therefore think that it is worthwhile to employ the covered box task paradigm, but the question of whether the experimental set-up 
Even more evidence for the emptiness of plurality

does an adequate job of facilitating implicature cancelation will take on particular importance in the case of plurals, a topic to which we will return.

\subsection{Experiment 1}

\subsubsection{Methods}

16 native English speakers participated in the experiment. Participants were undergraduates at Harvard University or members of the local community; they received study credit for their participation, or were compensated $\$ 5$.

Following the procedure developed by Huang and colleagues, the study was divided into a familiarization phase and a test phase, with the familiarization phase serving the purpose of introducing participants to the task. We departed from the original paradigm in using cards with pictures on them rather than boxes containing objects. In the first part of the familiarization phase, three cards were placed on the table, two face-up and one face-down. Participants were told, 'I am going to ask you for one of the cards. Sometimes it will be one of the ones that is face-up, sometimes it will be the one that is face-down'. Each card depicted Big Bird with some object, or set of objects, say a kite. Instructions of the form 'Point to the card where Big Bird has a kite' were given. The face-down card was turned over after the participant made a selection to show that it did indeed conform to the description if the other two cards did not, and that it did not match the description if one of the visible cards did. Participants received two trials where there was a visible card satisfying the description, and two where the face-down card was the correct match. They were then told, 'Now we're not going to check the cards anymore', and moved on to the second part of the familiarization phase; this was just like the first part except that the face-down card was not turned over. One additional participant was excluded due to incorrectly responding to the final familiarization trial.

During the test phase participants received three trials in one of two conditions, so that the design was entirely between-subjects, with eight participants assigned to each condition. The form of the instructions and the visible cards were always mismatched, resulting in the following conditions:

A. Instruction: Singular. 'Point to the card where Big Bird has a kite'.

Cards displayed:

(i) Big Bird with more than one kite.

(ii) Big Bird with nothing.

(iii) Face down card. 
B. Instruction: Plural. 'Point to the card where Big Bird has kites'. Cards displayed:

(i) Big Bird with one kite.

(ii) Big Bird with nothing.

(iii) Face down card.

In a pilot study, we found that when there was a card showing the appropriate number of the mentioned item, participants always chose it rather than a card with a mismatched number of items. We were therefore confident that if participants chose a number mismatched card, it was not because number marking was insufficiently salient. Like Huang and colleagues we used a between-subjects design to avoid highlighting the contrast between singular and plural sets, since this might encourage participants to treat them contrastively and make them aware of the purpose of the study. As in the second part of the familiarization phase, in the test phase participants did not turn over the face-down card after making their choice.

\subsubsection{Predictions}

If Sauerland is right that the multiplicity condition is an implicature, and supposing the experimental set-up was successful in facilitating cancelation of this implicature, then we would expect that in the plural condition, participants should select the visible card showing only one of the mentioned object, rather than choosing the facedown card. Moreover, cancelation should not be possible in the singular condition, since the atomicity requirement is built into the semantics of the singular.

\subsubsection{Results}

Participants overwhelmingly chose the face-down card in this experiment, insisting on an 'exactly one' interpretation for singulars and a 'more than one' interpretation for plurals. On average, participants chose the face-down card on $96 \%$ of trials, in both the singular and plural conditions. There was no significant, or numerical, difference between the singular and plural conditions in tendency to choose the face-down card across the three critical trials (Mann-Whitney $\mathrm{U}=32.0, p=1.000$ ).

\subsubsection{Discussion}

Participants chose the face-down card rather than violate the numerical inferences associated with the singular and the plural. Here are two possible interpretations of our results. One possibility is that the implicature-based theory of plural marking 
Even more evidence for the emptiness of plurality

is wrong, and participants failed to cancel an implicature in the critical conditions because there was no implicature there to cancel. On the other hand, it is possible that something about the experimental set-up or the form of the stimuli was insufficient to cause the implicature to be canceled. ${ }^{6}$ This would be consistent with the observation that if the multiplicity condition is generated via implicature, the resulting implicature is more difficult to cancel than, say, that associated with the scalar quantifier 'some'. Experiment 2 explores this second possibility.

\subsection{Experiment 2}

\subsubsection{Methods}

32 students from Harvard University and members of the local community participated. Again, participants received either course credit or \$5. The experimental set-up was the same as in Experiment 1, the sole change being the introduction of the word 'only' to the instructions on all trials, including familiarization. Thus, the critical trials had instructions of the form 'Point to the card where Big Bird only has kites/a kite', with the visual conditions as in Experiment 1. Neutral intonation was used, with the experimenter avoiding using focal stress on any particular lexical items.

We speculated that the addition of 'only' to our stimuli may create a linguistic context that would facilitate implicature cancelation for the plural. Firstly, we thought that 'only' might encourage the listener to look for a smaller set of items, so that if a single kite is compatible with the semantics of 'kites', then it would be even more acceptable as a small set of 'kites'. Secondly, we noted that 'only' is a presupposition trigger (Horn 1969), and speculated that the multiplicity implicature may not be obligatory when it occurs within presupposed material. In order to explore this idea, let's take a short excursion into the semantics of 'only'.

We shall assume a fairly traditional semantics for 'only', following Horn (1969) and Rooth $(1985,1992) .{ }^{7}$ Consider a sentence of form 'Only S', where S is a variable over sentences. Call S the prejacent; 'Only S' presupposes its prejacent (Horn 1969). Some constituent of $\mathrm{S}$ associates with focus, determining a set of alternatives to $\mathrm{S}$,

6 Pilot work with a different set of familiarization cards supports the notion that the experimental set-up affects the probability of implicature cancelation. When the familiarization cards did not demonstrate the possibility that Big Bird can have the same type of thing on more than one card, participants universally accepted the visible card even when it conflicted with the number marking in the description.

7 The semantics of 'only' is of course a much more controversial topic than our discussion will suggest. Alternatives to Horn's (1969) analysis have been proposed by Atlas (1993), Horn (1996), van Rooij (2005), and Ippolito (2007), among others. 
called ALT(S). The semantics for 'Only S' is stated in (7).

a. $\llbracket$ Only $S \rrbracket$ is defined only if $\llbracket S \rrbracket=1$

b. When defined, $\llbracket$ Only $\mathrm{S} \rrbracket=1$ iff $\forall \mathrm{S}^{\prime}\left[\left(\mathrm{S}^{\prime} \in \mathrm{ALT}(\mathrm{S}) \wedge \llbracket \mathrm{S}^{\prime} \rrbracket \nsubseteq \llbracket \mathrm{S} \rrbracket\right) \rightarrow \llbracket \mathrm{S}^{\prime} \rrbracket=\right.$ 0]

Consider our test sentence 'Point to the card where [Big Bird only has kites]'. Let's assume that the LF of the bracketed constituent is as in (8). ${ }^{8}$

Only [Big Bird has $\left.[D P \text { kites }]_{F}\right]$.

The presupposition of (8) is that Big Bird has kites, while it asserts that he has nothing that is not a kite. An interesting consequence of this analysis is that the multiplicity condition is only relevant to the presupposed content of the sentence, and not its truth conditions. While we have already seen linguistic data suggesting that the multiplicity implicature is obligatory when it contributes to what is asserted, there seems no a priori reason to think that it is obligatory when it contributes to what is presupposed but not what is asserted, as was the case with our stimuli in the plural condition in this experiment.

For our purposes, 'only' held two advantages over other presupposition triggers. Firstly, since its prejacent is presupposed but not asserted, plural marking contributed to the presupposed but not the asserted component, unlike with factive verbs, for example. ${ }^{9}$ Secondly, using 'only' allowed us to avoid the problem that an implicature-canceling context might also cancel an unrelated implicature attached to the use of the singular. To see how this implicature would work, consider the sentences in (9).

a. Big Bird has a kite.

b. Big Bird has more than one kite.

(9b) asymmetrically entails (9a). By the familiar reasoning process associated with the (Gricean) derivation of scalar implicatures, it is therefore expected that (9a) implicates that (9b) is false. ${ }^{10}$ However, if this implicature was canceled as well as any putative implicature on the plural, the results would be indiscernible from a strategy of simply ignoring number marking in favor of choosing a card showing the

8 Subscript ' $F$ ' indicates focus marking.

9 That the interpretation of plural morphology is not relevant to the asserted component is crucial: without this proviso, one might object that number marking also contributed to the presupposition in the stimuli used in Experiment 1, given that they involved definite descriptions.

10 This is a simplification. It is not the case that implicatures that can be expressed as the negation of a more informative alternative are freely generated; assuming this gives rise to well-known difficulties such as the so-called 'symmetry problem' discussed in Chierchia et al. to appear. We set this issue aside for the present purposes. 
Even more evidence for the emptiness of plurality

mentioned object. This is controlled for in Experiment 2, since 'Big Bird only has a kite' entails, rather than implicates, the falsity of $(9 b){ }^{11}$

\subsubsection{Results}

A clear difference between the singular and plural conditions emerged in this experiment. On average, participants in the singular condition chose the face-down card on $96 \%$ of trials, whereas those in the plural condition chose the face-down card on $35 \%$ of trials $(U=43.5, p<.001)$. In other words, when given the description 'only has a kite', participants almost always rejected an option that showed multiple kites, whereas the description 'only has kites' frequently led to accepting an option with a single kite. Moreover, when we compare these results to Experiment 1, we find no significant differences between the two singular conditions (all trials: $\mathrm{U}=68.0, p=.609$; first trial: $\chi=.522, p=.470$ ), but do find a significant decrease in the tendency to choose the face-down card, and accept the numerically mismatched visible card, in the plural condition (all trials: $\mathrm{U}=23.5, p<.01$; first trial: $\chi=5.371, p<.05$ ).

\subsubsection{Discussion}

The only change from Experiment 1 to 2 was the addition of 'only' to the descriptions, and yet here participants were willing to accept the number mismatched card. Recall that in the sentences used in our plural conditions, the interpretation of the plural morpheme is relevant to the presuppositional but not the asserted component. We claim that it is this property of our stimuli which encouraged participants in the plural condition in Experiment 2 to cancel the 'more than one' implicature. Sauerland's theory predicts that there should be both a strengthened presupposition for (10), 'Big Bird has more than one kite', and a weaker one with no implicature, 'Big Bird has at least one kite'.

Big Bird only has kites.

Our results suggest that two thirds of the time, a card satisfying the asserted component and the weaker presupposition was considered an adequate match. We have seen that the implicature of the plural is difficult to cancel when it is part of the asserted content of a sentence; however it need not follow that it is equally difficult to cancel in the presuppositional component. Precedents to the idea that

11 This entailment arises on the assumption that the DP 'a kite' is focus-marked, and not just the noun by itself. While we could not know in advance that this is how participants in the singular condition would interpret the stimuli, the results reported in section 3.3.2 suggest that this is indeed what happened. 
implicatures within presupposed material are less robust than those involved in the at-issue content exist in the literature. Russell (2006) notes that (11) is equally felicitous regardless of whether it is presupposed that some of George's advisors are crooks, or all are.

(11) George knows that some of his advisors are crooks. (Russell 2006: 362)

If Russell is right that (11) is felicitous in a context in which it is taken for granted that all of George's advisors are crooks, this would sit well with our finding that participants seemed to interpret the stimuli as carrying the weaker presupposition two thirds of the time. ${ }^{12}$ To this observation we would add that the felicity of the discourse in (12) supports the idea that when an implicature carried by a plural morpheme contributes to what is presupposed, it is relatively easy to cancel. Assuming that 'know' and 'realize' presuppose their complements, the second conjunct of (12) would be expected to create an empty context set if the plural had a strong semantics, or carried an obligatory implicature within presuppositional material.

(12) John knows that Mary has children, but he doesn't realize that she actually only has one.

We close this section by considering the possibility that selection of the mismatching card in the plural condition was not a consequence of implicature cancelation, but reflected a general strategy of ignoring presupposed content in favor of selecting a card satisfying the asserted content. Here is where our card showing Big Bird with no object comes into play. Observe that this card does not satisfy the presuppositions of our stimuli in either the singular or plural conditions, but neither does it contradict the asserted content. If the strategy described was at work, we should expect participants to choose the distractor card instead of the face-down one in the singular condition, but none of them did. We conclude that those participants who tolerated single exemplars in the plural condition were not simply sacrificing the presupposition for the sake of finding a match for the asserted component; rather they chose the card that satisfied the weak presupposition of the sentence.

One alternative interpretation that we cannot presently rule out, however, is that participants were sensitive to pragmatic constraints on the felicitous use of 'only'. In the singular condition, these constraints were satisfied, as the visible card with multiple kites could serve as a contrast to only having 'a kite'; however in the plural condition there was no plausible contrast item visible, so participants might have assumed that the contrast item was the face-down card, making them less likely to choose this card as the referent of the target sentence.

12 Russell uses this example for a different purpose from us. His view is that there is no scalar implicature in (11), and that the appearance of there being one arises from a contextual assumption about how well-informed the attitude-holder is. 
Even more evidence for the emptiness of plurality

\section{General discussion}

Let's take stock. We have two different results, gleaned by employing the covered box task with subtle variation in the wording of the test sentences. In Experiment 1, we found that participants rejected a single item as a possible referent for a plural DP, and rejected a set of multiple items as a possible referent for a singular DP. In Experiment 2, where the wording was altered so that participants now heard 'only has kites/a kite', participants became more tolerant of the single kite in the plural condition, but performance in the singular condition was unchanged.

One thing we can say with confidence is that if there is an implicature associated with the plural morpheme, it is difficult to cancel; this is demonstrated in Experiment 1, where participants consistently chose the face-down card. In Experiment 1, nothing more was done to encourage cancelation than to create a context in which there was a choice between a visible card compatible with the description providing that the implicature is canceled, and a face-down card. Huang and colleagues' work shows that with the scalar term 'some' this set-up is sufficient to facilitate cancelation; it is not sufficient to do so with the implicature associated with the plural - if indeed it is an implicature. We have already acknowledged on the basis of linguistic intuitions that an implicature-based theory of the plural would have to treat this implicature as less susceptible to cancelation than more familiar implicatures. Hence the results of Experiment 1 are not sufficient to discredit Sauerland's theory.

Our interpretation of the results in Experiments 2 is as follows. The difficulty of canceling the implicature associated with the plural is ameliorated by setting up a linguistic environment in which the meaning of plural marking contributes to the presupposed content of the stimuli, rather than what is asserted. If so, our findings have important consequences for our understanding of the interaction of implicature and presupposition, which may in turn bear on the question whether certain implicatures are computed by grammar or pragmatics.

In the remainder of this section, we consider three alternative interpretations of the results of Experiment 2. We shall reject the first two of these, but acknowledge that the third is compatible with our data.

First attempt: genericity One way of interpreting the data is to say that participants interpreted '... Big Bird only has kites' as involving quantification over kinds. A paraphrase would be, 'Big Bird has something belonging to the kite-kind, and for no other kind of item does Big Bird have something belonging to that kind'. Given our statement of the truth conditions of 'Big Bird only has kites', this analysis is tempting: the truth conditions are calculated with reference to alternatives that are formed by replacing the type of thing named in the prejacent with some other type of object. We do not think this is the right interpretation of our data, however. 
For one thing, the alienable possession relation denoted by 'have' in our stimuli is stage-level. Suppose we grant that bare plurals are kind-denoting (Carlson 1977), as is presumably necessary to implement the idea we are entertaining. Nonetheless, the semantics for our stimuli would have to make reference to realizations of the kind rather than the kind itself, given standard assumptions about stage-level predication. ${ }^{13}$ Let us say that a realization of a kind $k$ is an individual of cardinality 1 or more that intuitively belongs to $k$. Hence a single dog is a realization of the dog-kind, as is any group of more than one dog. The problem is that as soon as one resorts to predicating things of realizations of a kind, one is again faced with the problem of number. This can be seen by examining the following example, where the stage-level predicate 'be barking' combines with the bare plural 'dogs'. Stating the truth conditions of (13) involves existential quantification over realizations of the dog-kind, as shown in (14).

$$
\begin{aligned}
& \text { Dogs are barking. } \\
& \exists \mathrm{x}[\mathrm{R}(\mathrm{x}, \mathrm{d}) \text { \& barking }(\mathrm{x})] \text { (where } \mathrm{R}(\mathrm{a}, \mathrm{b}) \text { iff } \mathrm{a} \text { is a realization of } \mathrm{b})
\end{aligned}
$$

(14) is clearly not quite strong enough to capture the intuitive meaning of (13). Since a single dog is a realization of the dog-kind, (14) could be true in a context where only one dog is barking. What is needed is the proviso that there be an individual of cardinality greater than one with the properties of realizing the dogkind and barking. Otherwise, the import of plural morphology in (13) is not captured by the semantics.

These comments are intended to show that making reference to kinds does not neutralize the effects of number marking: wherever we find stage-level predication, we must make room for a contribution from number marking to the truth conditions of the sentence. Now, recall that 'Big Bird only has kites' presupposes that Big Bird has kites. A logical form for the presupposition can be stated by analogy with (14). ${ }^{14}$

$$
\exists \mathrm{x}[\mathrm{R}(\mathrm{x}, \mathrm{k}) \& \text { be-had-by-Big-Bird(x)] }
$$

We are in just the same position as we encountered with (14). The truth conditions are too weak to capture the import of number marking. To frame the issue slightly differently, given that we have learned that treating bare plurals as kind-denoting does not solve the problem of number marking because it rears its head again when one considers stage-level predication, treating the results of Experiment 2 in terms of genericity will not help, since the stimuli involve a stage-level relation. If one were to

13 The notion 'realization of a kind' and its involvement in the analysis of stage-level predications were first discussed in Carlson 1977.

14 We assume for expository purposes that Quantifier Raising of a covert existential operator enables a one-place predicate $[\lambda \mathrm{x}$.Big Bird has $\mathrm{x}]$ to be formed. 
Even more evidence for the emptiness of plurality

take this approach, one would be left with the question why the strengthening of the truth conditions in (14) that we have said is necessary is apparently unnecessary for (15). We won't pursue this account further, but will instead turn to two other possible explanations of the results of Experiment 2, both of which appeal to implicature.

Second attempt: downward entailment Von Fintel (1999) observes that in some cases, the addition of 'only' creates an environment in which Negative Polarity Items (NPIs) are licit, as demonstrated in (16).

a. *John has any books on his desk.

b. Only John has any books on his desk.

Facts like (16) pose something of a puzzle for the traditional theory of NPI licensing, since the structure in which 'any' is licensed in (16b) is not classically downward entailing, as can be verified by observing that (17a) does not entail (17b).

a. Only John has books on his desk.

b. Only John has books about linguistics on his desk.

Von Fintel responds by introducing a notion of 'Strawson downward entailment'; his definition is repeated below.

\section{Strawson Downward Entailingness}

A function $\mathrm{f}$ of type $\langle\sigma, \tau>$ is Strawson-DE iff for all $\mathrm{x}$,y of type $\sigma$ such that $\mathrm{x} \Rightarrow \mathrm{y}$, and $\mathrm{f}(\mathrm{x})$ is defined, $\mathrm{f}(\mathrm{y}) \Rightarrow \mathrm{f}(\mathrm{x})$. (von Fintel 1999: 104)

A function-argument term a(b) is defined only if its presuppositions are satisfied. Hence we can check whether (17a) Strawson-entails (17b) by checking that if (17b) is defined (if its presuppositions are satisfied), then (17a) entails (17b). We have said that sentences of form 'Only S' presuppose that S. So the question is whether, in a context in which John has books about linguistics on his desk, it cannot be true that only John has books on his desk without it being the case that only John has books about linguistics on his desk. Indeed it cannot; hence (17a) Strawson downward entails (17b). Von Fintel concludes that a Strawson-DE environment can license NPIs, and that this is what explains data like (16).

The idea that scalar implicatures are suspended in the contexts in which NPIs are licensed is by now fairly current in the literature (Chierchia 2004). One might expect on the basis of the discussion above that sentences employing 'only' also set up an environment in which SIs are suspended. The data in Experiment 2 would then be explained by saying that plural morphology is associated with an implicature which was suspended in the linguistic environment in which it occurred in our stimuli. This 
is a tempting thought, but we do not think it is right. Firstly, adding 'any' to our stimuli produces an ungrammatical result.

*Big Bird only has any kites.

This is unsurprising when one considers that the direct object position of this sentence is not Strawson-DE: in a context in which Big Bird has red kites, the inference from (20a) to (20b) is unwarranted.

(20) a. Big Bird only has kites.

b. Big Bird only has red kites.

One explanation for the failure of our stimuli to create a Strawson-DE environment might be that (20a) communicates the same information as (21a). The failure of the inference from (20a) to (20b) is therefore on a par with the failure of the inference from (21a) to (21b) in a context in which Big Bird has red kites.

(21) a. All Big Bird has are kites.

b. All Big Bird has are red kites.

Since the right-hand argument of a universal is upward entailing, it would indeed be surprising if it turned out to be Strawson-Downward Entailing, which notion is after all a more permissive variety of classical downward entailment. There is certainly more to say about these issues; we close this section by simply saying that the idea that a form of downward entailment played a role in suspending an implicature in the sentences used in Experiment 2 cannot be right.

Third attempt: the scope of a universal Sauerland et al. (2005) and Spector (2007) provide examples involving plural morphology in the scope of a universal quantifier where the multiplicity condition is absent, or at least does not seem to project universally. Consider for example the following:

(22) Yesterday, every student solved difficult problems. (Spector 2007: 259)

Spector reports that this sentence is not considered false in a context where every student solved at least one difficult problem, and a proper subset of them solved more than one difficult problem. ${ }^{15}$ We observed in the previous section that the communicative content of our stimuli in the plural condition of Experiment 2 can be thought of as a universally quantified sentence that can be paraphrased as 'All Big Bird has are kites', in which case plural morphology contributes to the scope of the universal quantifier. One might wonder whether whatever is responsible for the

15 On the relevant reading, the universal has wide scope with respect to the direct object. 
judgment in (22) is also responsible for the results of Experiment 2. We cannot do justice here to Spector's proposal concerning the interpretation of plural marking in the scope of a universal. We would point out, however, that underlying this alternative interpretation of our results is the intuition that 'only' is like 'every' except that it denotes the superset relation rather than the subset relation; it is this that gives rise to the equivalence of our stimuli with a universally quantified sentence in which plural marking appears in the scope rather than the restrictor. Pushing the analogy between 'only' and 'every' too far would have unwelcome consequences: it would imply that 'only' is a non-conservative determiner, and it would fail to do justice to the syntactic evidence that 'only' is not a determiner. However, we acknowledge that this interpretation of the results of Experiment 2 cannot be ruled out solely on the basis of the series of experiments described here. In future experiments, we plan to employ a broader range of presupposition triggers in order to discriminate between our proposal and the alternative just described.

\section{Conclusion}

Our study supports a theory of the meaning of plural morphology whereby the plural morpheme is associated with a multiplicity condition by means of implicature, as has been argued by Uli Sauerland and others. While the results of Experiment 1 are compatible with such a theory, the most compelling evidence in favor of it comes from Experiment 2: for a significant proportion of subjects, the implicature associated with the presupposed content in our stimuli was canceled. Our data also suggest that presuppositional environments facilitate implicature cancelation - a view which we have argued is the correct interpretation of Experiment 2. Future work will address these questions with a wider variety of presupposition triggers and controls, and with a much larger sample size.

\section{References}

Atlas, Jay. 1993. The importance of being only: testing the neo-Gricean versus neo-entailment paradigms. Journal of Semantics 10(4). 301-318. doi:10.1093/jos/10.4.301.

Barner, David \& Asaf Bachrach. 2010. Inference and exact numerical interpretation in early language development. Cognitive Psychology 60. 40-62. doi:10.1016/j.cogpsych.2009.06.002.

Carlson, Gregory. 1977. A unified analysis of the English bare plural. Linguistics and Philosophy 1(3). 413-457. doi:10.1007/BF00353456.

Chierchia, Gennaro. 1998. Plurality of mass nouns and the notion of 'semantic parameter'. In S. Rothstein (ed.), Events and Grammar, 53-103. Boston: Kluwer. 
Chierchia, Gennaro. 2004. Scalar implicatures, polarity phenomena, and the syntax/pragmatics interface. In A. Belletti (ed.), Structures and Beyond, 39-103. Oxford: Oxford University Press.

Chierchia, Gennaro. 2007. Handout for 'Topics in Semantics'. Harvard University. Chierchia, Gennaro, Danny Fox \& Benjamin Spector. to appear. The Grammatical View of Scalar Implicatures and the Relationship between Semantics and Pragmatics.

Fauconnier, Gilles. 1975. Polarity and the scale principle. In Proceedings of Chicago Linguistics Society 11, 188-199.

Fauconnier, Gilles. 1979. Implication reversal in a natural language. In F. Guenthner \& S. J. Schmidt (eds.), Formal semantics and pragmatics for natural language, Dordrecht: Reidel.

von Fintel, Kai. 1999. NPI Licensing, Strawson Entailment, and Context Dependency. Journal of Semantics 16(2). 97-148. doi:10.1093/jos/16.2.97.

Grice, Herbert Paul. 1975. Logic and conversation. In P. Cole \& J. L. Morgan (eds.), Syntax and semantics: Speech acts, Vol. 3, 41-58. New York: Academic Press.

Heim, Irene. 1991. Artikel und Definitheit. In A. von Stechow \& D. Wunderlich (ed.), Semantics: An international handbook of contemporary research, 487-535. Berlin/New York: W. de Gruyter.

Horn, Laurence. 1969. A presuppositional approach to 'only' and 'even'. In Proceedings of CLS 5, 98-107.

Horn, Laurence. 1996. Exclusive company: 'only' and the dynamics of vertical inference. Journal of Semantics 13(1). 1-40. doi:10.1093/jos/13.1.1.

Huang, Yi Ting, Jesse Snedeker \& Elizabeth Spelke. under review. What Exactly do Numbers Mean?

Ippolito, Michela. 2007. On the meaning of Only. Journal of Semantics 25(1). 45-91. doi:10.1093/jos/ffm010.

Ladusaw, William. 1979. Polarity sensitivity as inherent scope relations: University of Texas at Austin dissertation.

Ladusaw, William. 1980. Affective 'or', factive verbs, and negative polarity items. In Proceedings of Chicago Linguistics Society 16, 170-184.

Ladusaw, William. 1980b. On the notion 'affective' in the analysis of negative polarity items. Journal of Linguistic Research 1. 1-23.

Noveck, Ira \& Anne Reboul. 2008. Experimental pragmatics: a Gricean turn in the study of language. Trends in Cognitive Sciences 12(11). 425-431. doi:10.1016/j.tics.2008.07.009.

Pouscoulous, Nausicaa \& Ira Noveck. in press. Developmental aspects of the semantic/pragmatic distinction. In S. Foster-Cohen (ed.), Advances in language acquisition, London: Palgrave Macmillan.

van Rooij, Robert \& Katrin Schulz. 2005. Only: Meaning and implicatures. Univer- 
Even more evidence for the emptiness of plurality

sity of Amsterdam.

Rooth, Mats. 1985. Association with focus. Amherst, MA: GLSA Publications.

Rooth, Mats. 1992. A theory of focus interpretation. Natural Language Semantics 1(1). 75-116. doi:10.1007/BF02342617.

Russell, Benjamin. 2006. Against grammatical computation of scalar implicatures. Journal of Semantics 23(4). 361-382. doi:10.1093/jos/ffl008.

Sauerland, Uli. 2003. A new semantics for number. In Proceedings of SALT 13, 258-275. Cornell University, Ithaca, NY: CLC Publications.

Sauerland, Uli, Jan Anderssen \& Kazuko Yatsushiro. 2005. The plural is semantically unmarked. In S. Kepser \& M. Reis (ed.), Linguistic Evidence, 413-434. Berlin: Mouton de Gruyter.

Schwarzschild, Roger. 1996. Pluralities. The Netherlands: Kluwer.

Spector, Benjamin. 2007. Aspects of the pragmatics of plural morphology: On higher-order implicatures. In U. Sauerland \& P. Stateva (ed.), Presuppositions and implicatures in compositional semantics, 243-281. Houndsmill, UK: Palgrave-Macmillan.

Zweig, Eytan. 2009. Number-neutral bare plurals and the multiplicity implicature. Linguistics and Philosophy 32(4). 353-407. doi:10.1007/s10988-009-9064-3.

Hazel Pearson

Department of Linguistics

Boylston Hall

Cambridge, MA 02138

USA

hpearson@fas.harvard.edu

Jesse Snedeker

Department of Psychology

33 Kirkland St.

Cambridge, MA 02138

USA

snedeker@wjh.harvard.edu
Manizeh Khan

Lab for Developmental Studies

Shannon Hall Room 202

25 Francis Avenue

Cambridge, MA 02138

USA

khan@wjh.harvard.edu 